\title{
DESENVOLVIMENTO DO RACIOCINIO GEOMÉTRICO: UMA EXPERIÊNCIA COM O GEOGEBRA
}

\section{DEVELOPMENT OF REASONING GEOMETRIC: AN EXPERIENCE WITH GEOGEBRA}

\author{
Solange Sardi Gimenes \\ Prefeitura Municipal de Vitória \\ E-mail: gimenes.solangesardi10@gmail.com \\ Rony Claudio de Oliveira Freitas \\ Instituto Federal do Espírito Santo \\ E-mail: ronyfreitas@ifes.edu.br
}

\section{Resumo}

Neste artigo apresentamos uma análise do processo de desenvolvimento do pensamento geométrico de estudantes ao fazerem uso do software de geometria dinâmica Geogebra. Optamos por uma abordagem metodológica de natureza qualitativa e o trabalho de campo envolveu duas turmas de 90 ano do ensino fundamental. Para produzir os dados, propusemos aos alunos a realização de construções geométricas e no decorrer deste processo de construção os alunos foram motivados a explicar resultados, verificar propriedades, analisar teoremas, perceber relações. Esses dados são analisados a partir da descrição de alguns episódios ocorridos no laboratório de informática.

Palavras-chave: atividades exploratórias e investigativas. Geogebra. pensamento geométrico.

\begin{abstract}
In this article, we present one analysis of development process of students' geometric knowledge when they use the software GeoGebra. We chose a qualitative methodological approach and the fieldwork involved two groups of 9th grade of elementary school. To produce the data, we proposed to students create geometric constructions and during this constructions the students were motivated to explain results, verify properties, analyze theorems, understand relationships. This data are analyzed from some episodes that occurred in the laboratory with computers.
\end{abstract}

Palavras-chave: exploratory and investigative activities. Geogebra. geometric thinking 


\section{INTRODUÇÃO}

O campo da geometria, parte importante do saber matemático, oferece uma riqueza de possibilidades quando o objetivo é colaborar com o processo de pensamento do aluno, pois estabelece uma forma específica de raciocinar. Esse campo faz uso de procedimentos, exige a percepção de relações conceituais, possibilita representações simbólicas de objetos geométricos presentes no campo de visão, ou não, e assim pode levar a muitas possibilidades de produção de conhecimento. A representação de tais objetos pode ocorrer por meio de construções realizadas com programas computacionais de geometria dinâmica que possibilitam a visualização de entes abstratos na área de trabalho. "A visualização auxilia no raciocínio intuitivo, representando uma primeira etapa para a compreensão de conceitos e a prova de teoremas" (BORBA, 2010, P.3-4).

A visualização é uma das características do processo de pensamento, trata-se do primeiro estágio, de um total de cinco segundo o modelo de pensamento geométrico descrito pelo casal van Hiele. Ao oferecer ao aluno experiências desse tipo pode-se desencadear o desenvolvimento da capacidade de representar mentalmente objetos, sem a presença dos mesmos. A partir daí o aluno passa a ter um entendimento de forma abstrata de propriedades, relacionando-as a uma determinada figura, ou entre figuras sem a presença do objeto físico. A análise da representação de objetos geométricos pode ocorrer por meio de situações concretas e conforme o aluno avança no seu raciocínio geométrico ocorre a transição do concreto para o abstrato. De acordo com Gimenes (2014, p.13) "o aluno pode observar diferentes formas e, a partir da representação dessas formas, pode investigar regularidades, semelhanças e diferenças, desenvolvendo formas de raciocínio".

Kaleff (2008) destaca que, para desenvolver a habilidade da visualização, é importante oferecer ao aluno experiências com as quais esse visualize a representação de objetos geométricos. Van Hiele (1986, apud Kaleff, 1998) aponta a importância da visualização na produção do conhecimento geométrico, já que a representação mental dos objetos geométricos envolve a análise de propriedades geométricas. 
A intenção deste texto é levantar algumas reflexões em torno da produção de conhecimento geométrico quando são utilizados recursos computacionais no campo da geometria. Faz-se isso partindo da ideia que, ao oferecer ao aluno oportunidade de realizar investigações das próprias construções geométricas, criam-se ambientes propícios para a experimentação, o que pode colaborar com o desenvolvimento do raciocínio geométrico do aluno.

Uma abordagem experimental em educação matemática significa fazer uso de procedimentos de tentativas e processos educativos que possibilitem a criação de conjecturas, a descoberta de resultados matemáticos desconhecidos, a oportunidade de testar modos alternativos de coletar resultados e a chance de proporcionar novos experimentos (BORBA; VILLARREAL, 2005, APUD BORBA, 2010, p. 4).

Acreditamos que os programas de computador podem potencializar a experimentação. Com eles o aluno dispõe dos elementos geométricos, das ferramentas de medida, de recursos que possibilitam o movimento das construções geométricas que "permitem que figuras sejam arrastadas pela reta, mantendo-se os vínculos estabelecidos nas construções" (ZULATO, 2007, P. 78). São muitos os programas computacionais voltados para o campo da geometria, para esta pesquisa fizemos uso do programa Geogebra.

Neste artigo relatamos alguns episódios ocorridos no trabalho de campo de uma pesquisa de mestrado intitulada "Contribuições de atividades de investigação e exploração com o computador na produção de conhecimento acerca do assunto semelhança", de autoria de Gimenes (2014), que procurou identificar produção de conhecimento geométrico ao propor aos alunos, de forma experimental, construções geométricas por meio de recursos computacionais e atividades investigativas. Fizemos, neste trabalho, um recorte de alguns episódios que oferecem subsídios para reflexões em torno da utilização de recursos computacionais ao considerar características do pensamento geométrico. 


\section{RECURSOS COMPUTACIONAIS E GEOMETRIA}

O Geogebra é um software de acesso livre, gratuito e multiplataforma. Reúne numa perspectiva de matemática dinâmica um ambiente para o trabalho com a geometria, álgebra e cálculo. Programas de geometria dinâmica em geral proporcionam dinamismo, interatividade e precisão nas construções geométricas, permitindo ao usuário criar e manipular objetos geométricos por meio de suas propriedades. Ponte, Brocardo e Oliveira destacam o uso desses programas numa proposta exploratória investigativa.

Comecemos pela utilização de programas de Geometria Dinâmica, uma opção curricular atualmente bastante enfatizada. Esse suporte tecnológico permite o desenho, a manipulação e a construção de objetos geométricos, facilita a exploração de conjecturas e a investigação de relações que precedem o uso do raciocínio formal (PONTE, BROCARDO E OLIVEIRA, 2009, p.83).

Um programa de geometria dinâmica proporciona precisão nas construções. Um aspecto nessas construções que merece ser observado é o teste do "arrastar". Uma construção geométrica necessita de certos critérios ao ser construído para que ao utilizar a ferramenta "Mover" a figura seja arrastada na área de trabalho do programa e mantenha as propriedades geométricas que constituem tal figura. Laborde (1998) chama de desenho geométrico as construções que não atendem a esse quesito.

Laborde (1998), citado por Zulatto (2007), descreve a diferença entre "desenhar" e "construir" uma figura, ao utilizar um programa de geometria dinâmica.

Por exemplo, três segmentos de mesmo tamanho, que formam ângulos internos de $60^{\circ}$, podem ser considerados um desenho de um triângulo equilátero. Mas somente terá sido construído um triângulo equilátero se seus vértices puderem ser arrastados de forma a manter as propriedades 
dessa figura (LABORDE, 1998, apud. ZULATTO, 2007, p. 78).

Manter as propriedades geométricas da figura ao utilizar a ferramenta "Mover" pode proporcionar ao aluno maiores oportunidades de perceber a variância ou invariância de medidas, contribuindo no sentido de verificar teoremas, analisar propriedades.

No caso de alunos iniciantes no uso das ferramentas de um programa de geometria dinâmica, um "desenho" geométrico pode atender as expectativas da atividade. Gimenes (2014) concluiu em sua pesquisa após realização de atividades investigativas com o computador que,

Mesmo tratando-se de um "desenho" geométrico, é possível, de forma dinâmica e interativa e por meio desses programas de geometria, oferecer oportunidades de se verificar variações de construções geométricas, analisar propriedades e investigar teoremas (GIMENES, 2014, p.29).

Um desenho geométrico pode auxiliar no desenvolvimento da visualização, por exemplo, e assim fortalecer a base de produção do conhecimento geométrico. Foi a partir dessa premissa que a intervenção em sala de aula foi feita. A proposta foi oferecer aos estudantes oportunidades de experimentações, viabilizadas pelas facilidades de realizar construções geométricas na qual os recursos tecnológicos pudessem potencializar a produção de conhecimento.

Como forma de abordar o assunto utilizamos atividades de natureza exploratórioinvestigativas. São atividades que não limitam uma questão a uma determinada resposta, são questões abertas que comportam diferentes possibilidades. Brocardo (2011, p. 132), descreve as atividades exploratórias investigativas "como uma primeira experiência que permite ter uma visão geral de um contexto que será trabalhado posteriormente", e assim, segundo Gimenes (2014), pode oferecer oportunidade de explorar uma ideia antes que se apresente uma definição. Também "pode ser explorada após a construção de determinados 
conceitos, o que nesse caso pode ampliar o conhecimento ou dar um novo sentido ao conhecimento que o aluno já produziu" (GIMENES, 2014, p.11).

Investigar, conforme Ponte, Oliveira e Brocardo (2009) e Skovsmose(2001), significa partir de questões que nos chamam a atenção e ao buscar respostas para situações de dúvidas e incertezas, que inicialmente pode nos parecer confusas, produzimos conhecimento. "Desse modo, investigar não representa obrigatoriamente trabalhar em problemas muito difíceis" (PONTE; OLIVEIRA; BROCADO, 2009, p. 9), significa investigar propriedades e relações partindo do conhecimento que já temos, e assim, conforme surgem as incertezas e as dúvidas, buscamos por respostas, aumentando nossas oportunidades de produção de conhecimento. As atividades investigativas podem estimular o aluno a expressar e trocar ideias, ao ter que descrever suas conclusões.

\section{CARACTERÍSTICAS DO PROCESSO DE PENSAMENTO GEOMÉTRICO}

Ao fazer uso dos recursos tecnológicos para responder questões de natureza exploratória investigativa, consideramos as situações que foram surgindo, conforme surgiam os momentos de dúvidas e incertezas aproveitava-se para explorar determinado assunto da geometria. Embora a aprendizagem fosse almejada, ela foi considerada no processo e não como meta final.

Não concordamos com o modelo de níveis de pensamento que defende uma aprendizagem de forma linear, sequencial e prescritiva como proposto pelo casal van Hiele. Utilizamos desse modelo as características do pensamento geométrico, cuja observação consideramos importante na produção de conhecimento geométrico dos estudantes. As ideias que constam na teoria de níveis defendida pelos van Hiele foram utilizadas nesta proposta como orientação, apenas para identificar obstáculos no processo de produção de conhecimento. Considerar características do desenvolvimento do pensamento geométrico trouxe colaborações na análise das dificuldades apresentadas pelos alunos, na condução das 
discussões, auxiliando a professora na tomada de decisões e na organização das atividades a serem propostas.

A teoria de níveis dos van Hiele apresenta cinco níveis de compreensão: visualização, análise, dedução informal, dedução formal e rigor, os quais apresentam características do processo de pensamento. No quadro 1 temos uma breve descrição desses níveis e as características apontadas por Crowle (1994, p. 2-4).

Quadro 1. Divisão dos níveis de van Hiele.

\begin{tabular}{|c|c|l|}
\hline Nível & Denominação & \multicolumn{1}{|c|}{ Característica do processo de pensamento } \\
\hline I & Visualização & $\begin{array}{l}\text { Os conceitos de geometria são vistos como entidades totais, e não como } \\
\text { entidades que tem componentes e atributos. }\end{array}$ \\
\hline II & Análise & $\begin{array}{l}\text { Surgem, então, propriedades que são utilizadas para conceituar classes de } \\
\text { configurações. Assim, reconhece-se que as figuras têm partes, e as figuras são } \\
\text { reconhecidas por suas partes. }\end{array}$ \\
\hline III & Dedução informal & $\begin{array}{l}\text { O significado da dedução como uma maneira de estabelecer a teoria } \\
\text { geométrica no contexto de um sistema axiomático. }\end{array}$ \\
\hline IV & Rigor & $\begin{array}{l}\text { O aluno é capaz de trabalhar em vários sistemas axiomáticos, isto é, pode } \\
\text { estudar geometrias não euclidianas e acompanhar sistemas diferentes. A } \\
\text { geometria é vista no plano do abstrato. }\end{array}$ \\
\hline
\end{tabular}

Esse modelo de níveis de raciocínio geométrico podem oferecer informações importantes no processo de análise de produção de conhecimento, no entanto alguns aspectos defendidos nesta teoria não se enquadram numa proposta em que os alunos têm liberdade para encontrar resultados em atividades não estruturadas. Em alguns casos muda-se o foco do assunto, afastando-se da teoria de níveis, que defende o avanço desses níveis de forma hierárquica, linear, onde só se alcança determinado nível se passar pelo nível anterior, ao desenvolver certas habilidades e acumular determinado conhecimento.

Outro aspecto a ser observado em torno do uso de recursos tecnológicos no campo da geometria, considerando a teoria de níveis do casal van Hiele, é a estruturação conceitual defendida nessa teoria. De Villiers (2010, p. 409) descreve esse aspecto afirmando que "este modelo enfatiza que atividades informais, nos Níveis 1 e 2, deveriam fornecer as 
subestruturas conceituais adequadas para as atividades formais do nível seguinte". No entanto, esse mesmo autor considera inadequadas as atividades experimentais para a descoberta de propriedades e cita como exemplo a forma de abordar o teorema da soma dos ângulos internos de um triângulo. Ele ainda afirma que para van Hiele não se deve fornecer instrumentos de medida, isso é totalmente inadequado "já que não proporciona uma subestrutura conceitual apropriada, na qual a explicação lógica eventual (prova) está implicitamente embutida" (DE VILLIERS, 2010, p. 409). Complementa dizendo que ao fazer uso de um programa de geometria dinâmica para realizarem tal atividade o ideal é transladar e rotacionar um triângulo envolvendo o ponto médio, e assim o aluno perceberia a formação do ângulo raso ao reunir os três vértices do triângulo. "No caso de uma proposta investigativa, os alunos ficam livres para encontrar determinados resultados e tais substruturas conceituais podem ser construídas de forma diferente do que propõe o modelo" (GIMENES, 2014, p. 38).

\section{PERCURSO METODOLÓGICO}

As atividades se desenvolveram no contexto de uma sala de aula/laboratório de informática de uma escola da rede municipal de ensino, situada em Vila Velha-ES, onde os sujeitos da pesquisa, alunos do $9^{\circ}$ ano do ensino fundamental, foram desafiados a realizar construções geométricas utilizando o programa de geometria dinâmica Geogebra.

A coleta dos dados produzidos ocorreu por meio da observação, da descrição escrita e gravações de áudio e vídeo dos diálogos que surgiram entre professor e aluno. Nesse caso a coleta de dados e informações basearam-se numa concepção de pesquisa qualitativa. Há de se considerar que temos uma diversidade de informações geradas conforme surgiam dúvidas e incertezas ao procurar atingir determinados objetivos nas construções geométricas, ou nas indagações realizadas pela professora, que produzem reações variadas difíceis de enquadrar num objetivo exato. De acordo com Goldenberg, “também é evidente o valor da pesquisa qualitativa para estudar questões difíceis de quantificar, como sentimentos, motivações, 
crenças e atitudes individuais" (2004, p. 63).

Outro aspecto na pesquisa qualitativa que merece destaque é o olhar do pesquisador na análise dos resultados. Garnica (2004, p.86) também destaca a não neutralidade do pesquisador na interpretação dos fatos. Para esse autor, o pesquisador "vale-se de suas perspectivas e filtros vivenciais prévios dos quais não consegue se desvencilhar".

A pesquisa qualitativa adotada nesta proposta vai ao encontro das ideias de Javaroni, Santos e Borba quando dizem que

podemos definir pesquisa qualitativa como um modelo, uma forma de se fazer pesquisa, onde o foco, o olhar da pesquisa encontra-se nas relações que tem significado para o pesquisador. De forma geral, quando estamos elaborando ou executando uma pesquisa em Educação Matemática, estamos buscando entender as relações que acontecem com os "objetos" de nosso estudo, ancorados em uma perspectiva teórica que sustenta nossa forma de conceber o mundo que vivemos (JAVARONI, SANTOS E BORBA, 2007, p. 2).

\section{RESULTADOS E DISCUSSÕES}

A seguir apresentamos a descrição de três atividades que foram aplicadas após a finalização da pesquisa, são atividades extras cujo objetivo foi estabelecer uma estratégia de ensino complementar à sequência de atividades que foram surgindo no decorrer da pesquisa. 0 conteúdo abordado foi semelhança de triângulos, no entanto as dúvidas e incertezas caminharam em direção a diferentes conceitos no campo da geometria. As atividades apresentadas neste artigo são um recorte de um todo, com as quais se procurou sanar algumas lacunas no conhecimento geométrico identificados pela professora, já que a dificuldade em avançar em algumas questões mostrou que determinados assuntos mereciam uma nova oportunidade de exploração. 
As atividades seguiram um mesmo padrão de aplicação. Utilizamos o programa Geogebra e os alunos recebiam algumas informações sobre os procedimentos de construção, e conforme surgiam dúvidas, a professora realizava as intervenções necessárias e procurava conduzir as discussões, de forma a levar informações matemáticas até o aluno partindo de uma necessidade encontrada após realizar construções geométricas.

Esta atividade pode ser realizada de diferentes formas, com ou sem o uso da tecnologia. Numa primeira aplicação utilizaram os recursos do programa Geogebra e procuraram construir os triângulos assinalados, conforme as propriedades descritas. Após isso, marcaram com um $x$ as propriedades de cada triângulo, finalizando com a definição deles.

Quadro 2. Atividade I.

\begin{tabular}{|l|l|l|l|l|l|l|l|}
\hline \multicolumn{1}{|c|}{ Triângulo } & $\begin{array}{c}\text { Três lados } \\
\text { iguais }\end{array}$ & $\begin{array}{c}\text { Pelo menos } \\
\text { dois lados } \\
\text { iguais }\end{array}$ & $\begin{array}{c}\text { Três lados } \\
\text { diferentes }\end{array}$ & $\begin{array}{c}\text { Três } \\
\text { ângulos } \\
\text { agudos }\end{array}$ & $\begin{array}{c}\text { Um ângulo } \\
\text { reto }\end{array}$ & $\begin{array}{c}\text { Um ângulo } \\
\text { obtuso }\end{array}$ & Definição \\
\hline Equilátero & & & & & & & \\
\hline Isósceles & & & & & & & \\
\hline Escaleno & & & & & & & \\
\hline Obtusângulo & & & & & & & \\
\hline Acutângulo & & & & & & & \\
\hline Retângulo & & & & & & & \\
\hline
\end{tabular}

Baseado nas informações da tabela, responda:

a) Um triângulo equilátero pode ser um triângulo obtusângulo? ( ) Sim ( ) Não Justifique:

b) Um triângulo retângulo pode ser um triângulo isósceles? （ ) Sim （） Não Justifique:

c) Um triângulo retângulo pode ser um triângulo equilátero? （ ) Sim （） Não Justifique:

d) Um triângulo retângulo pode ser um triângulo escaleno? （ ) Sim （） Não Justifique:

e) É possível encontrar dois ângulos retos num triângulo? （）Sim （）Não Justifique:

Fonte: acervo dos pesquisadores, 2014. 
Esta atividade teve como objetivo classificar triângulos de acordo com as medidas de lados e de ângulos, além de oferecer ao aluno informações, para em seguida serem provocados a analisar determinada classificação ao terem que justificar suas opções de resposta.

Quanto às características do processo de pensamento, esta atividade possibilitou que realizassem a ordenação lógica de propriedades das figuras por meio de curtas sequências de dedução e ofereceu oportunidade de compreenderem as correlações entre as figuras, identificando propriedades de objetos que os classificam.

A atividade descrita na Figura 1 mostra as justificativas do aluno, conforme sua opção, a qual exigiu uma compreensão significativa das classificações descritas.

Figura 1. Justificativas do aluno.

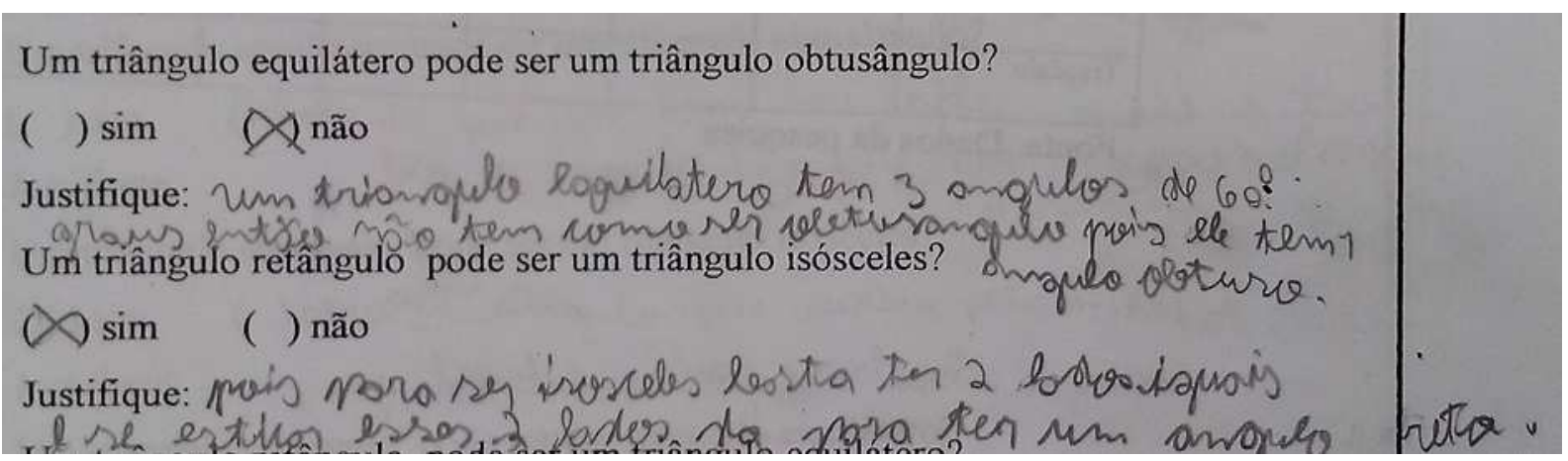

Fonte: Acervo dos pesquisadores, 2014.

Os estudantes foram provocados a realizarem suas próprias construções a partir de determinadas características fazendo uso de experimentações. Isso contribuiu para o desenvolvimento de aspectos importantes do raciocínio geométrico conforme aponta Gimenes (2014). Para ela um programa de geometria dinâmica pode favorecer a visualização de características de figuras geométricas e dispõe de ferramentas de medidas e de movimento que podem conduzir o aluno a realizar testes, verificar resultados, os quais, nesta atividade, contribuiu para comprovarem propriedades que caracterizam as classificações de triângulos. As tentativas de construção geraram comentários, dúvidas, provocaram curiosidade e, principalmente, serviram para mostrar a importância da materialização da 
figura geométrica com o uso do computador.

A atividade II teve como objetivo conduzir os estudantes a perceberem que um triângulo apresenta três alturas. Esta atividade foi desenvolvida como atividade extra, após um momento de discussão em torno das medidas necessárias para realizar o cálculo da medida de área em triângulos retângulos semelhantes. Para realizarem esta atividade, os alunos receberam as seguintes orientações:

Quadro 3. Atividade II.

Altura de triângulo é o segmento de reta perpendicular que une um vértice ao lado oposto ou a seu prolongamento. Nesse caso, o lado oposto é chamado base do triângulo. Acompanhe os passos abaixo, complete a tabela e responda as questões.

- $\quad$ No menu Exibir, desmarque a opção Eixos.

- $\quad$ Selecione a ferramenta Polígono e construa um triângulo qualquer.

- $\quad$ Trace a altura do triângulo utilizando a ferramenta Reta Perpendicular, clicando no lado do triângulo que deseja considerar como base e no vértice do lado oposto.

- Utilize a ferramenta Interseção de dois objetos e marque a interseção da altura com o lado considerado como base. Utilize a ferramenta Distância, Comprimento ou Perímetro e encontre as medidas da base e da altura do triângulo.

- $\quad$ Repita o procedimento para os demais lados do triângulo e complete a tabela descrita no quadro 08:

\begin{tabular}{|l|l|l|l|}
\hline Triângulo & Base & Altura & Área $=$ b.h/2 \\
\hline$\triangle \mathrm{ABC}$ & & & \\
\hline$\triangle \mathrm{ABC}$ & & & \\
\hline$\triangle \mathrm{ABC}$ & & & \\
\hline
\end{tabular}

Agora responda:

a) Para você, qual a definição de altura de um triângulo?

b) Ao modificar a base e a altura do triângulo, os resultados foram alterados ou permaneceram os mesmos? Justifique sua resposta.

c) A qual conclusão você chega após realizar essa atividade? Você aprendeu algo de novo?

Fonte: acervo dos pesquisadores, 2014. 
A atividade que motivou a abordagem do elemento altura no triângulo surgiu ao procurar conduzir a turma a analisarem o coeficiente de proporcionalidade ao comparar os lados homólogos, o perímetro e a área de triângulos semelhantes, e assim perceberem a relação entre os coeficientes de proporcionalidade dos lados homólogos dos triângulos semelhantes com área e perímetro. No entanto, as discussões giraram em torno dos elementos utilizados para o cálculo de área de um triângulo, como mostra o seguinte recorte do diálogo I.

Solange: Deixa eu olhar aqui, Aluno I, você fez 5, 4 e 3 (mostrando a medida dos lados do triângulo). O que você fez aqui? Você multiplicou por quanto? Aluno I: Multipliquei por 2, 3 e 4 (referindo-se a medida dos lados dos três triângulos que foram ampliados, multiplicando por 2, 3 e 4).

Solange: 2, 3 e 4. E a sua área, aconteceu o quê? Você conseguiu chegar a alguma conclusão?

Aluno I: É, eu estava olhando, mas não consegui não.

Solange: Pra achar a área o Geogebra, o programa, multiplicou o que ali, Aluno I?

Aluno I: A base vezes a altura, ali do lado (aponta para os resultados fornecidos pelo programa).

Solange: Isso, mas o que é base e o que é altura nesse triângulo retângulo seu ali?

Aluno I: A base é a hipotenusa e o cateto (mostra apontando com o dedo). Solange: Ele multiplicou hipotenusa vezes o cateto e ele encontrou isso, cinco vezes quatro é vinte, dividido por dois, deu a área? (A professora interroga o aluno, conduzindo-o a perceber que a metade do produto da medida da hipotenusa pela medida do cateto não apresenta os mesmos resultados apresentados pelo programa).

Solange: Qual é a base e qual é a altura?

Aluno I: Não. Ele multiplicou os dois catetos, quatro vezes três é igual a doze e doze dividido por 2 é igual a seis.

Solange: Aqui também, oito vezes seis (mostra os valores nos quais a 
metade dos catetos resulta no valor da área).

Aluno I: Dá quarenta e oito, dividido por 2, dá vinte e quatro.

As dúvidas levantadas pelos estudantes mostraram que eles entendiam somente a altura relativa à hipotenusa e neste caso, exploramos novamente este assunto de forma mais direta na intenção de sedimentar junto aos alunos a ideia de existência de outras alturas num mesmo triângulo.

A intenção da professora foi conduzi-los a observarem os resultados fornecidos pelo software. Num outro recorte, no diálogo II, um grupo de alunos já apresentou um avanço quanto à análise dos elementos utilizados para o cálculo de área do triângulo:

Solange: Então, na verdade, o que você multiplicou pra chegar à área?

Aluno G: Cateto, cateto.

Solange: Você multiplicou, isso aqui é um cateto. Que, na verdade, é o quê, no meu triângulo, é a base não é? Você multiplicou pelo que?

Aluno G: Pelo cateto altura.

Solange: Na verdade você multiplica os catetos, não foi isso? Cateto vezes cateto dividido por dois. Por que esse cateto aqui foi chamado de altura? Nesse caso ali?

Aluno G: Porque ele determina a altura do triângulo

Aluno H: Porque o ângulo de $90^{\circ}$ está aqui.

Solange: Isso aí, é uma linha perpendicular. Mas, além dessa altura, temos essa altura (a professora explica sobre a altura relativa à hipotenusa), é outra altura, tá vendo?

Solange: Se eu multiplicar essa base aqui (mostra a hipotenusa), vou encontrar a mesma área?

O diálogo nos mostra a professora provocando os alunos a explicarem os resultados que haviam encontrado nas construções. Crowley (2004) discute esse aspecto da seguinte forma: “a natureza das explicações geométricas de um aluno reflete seu nível de raciocínio, a 
indagação é um importante instrumento de avaliação" (CROWLEY, 2004, p. 18).

O Geogebra ofereceu agilidade nas construções e nos cálculos, possibilitando uma melhor compreensão a partir de processos visuais dos elementos que compõem um triângulo. Os alunos tiveram a oportunidade de explorar alturas internas e externas, conforme observamos no triângulo $A B C$, da Figura 2, enriquecendo a atividade.

Figura 2. Altura de triângulo.

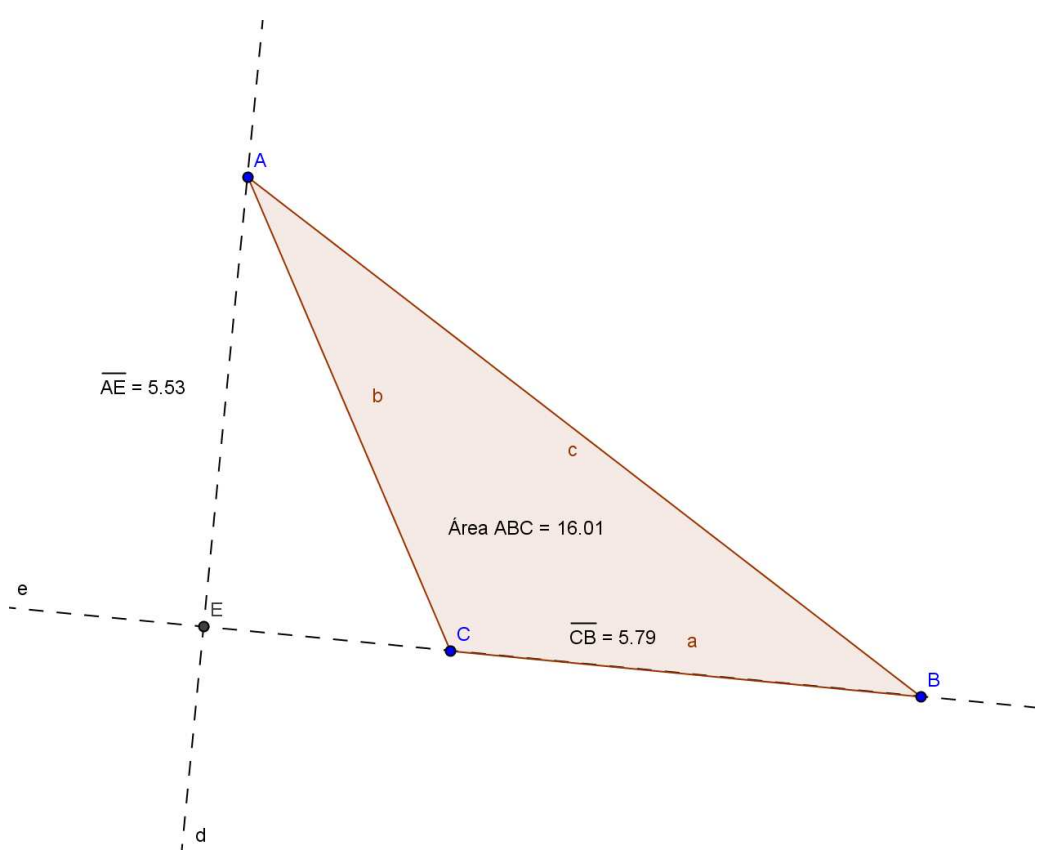

Fonte: Acervo dos pesquisadores, 2014.

Fazendo uma análise das características do pensamento geométrico, Crowley (2004) destaca que, no nível da dedução informal, o aluno, ao resolver problemas, considera importantes as propriedades das figuras ao descrever a altura do triângulo, considerando o ângulo de $90^{\circ}$, conforme mostra a fala do aluno $\mathrm{H}$ : Porque o ângulo de $90^{\circ}$ está aqui; nota-se que o aluno produziu conhecimento importante em torno da figura geométrica.

Esta atividade trouxe contribuições na análise do pensamento geométrico pois proporcionou aos alunos partir de um raciocínio indutivo, começar com casos particulares considerando diferentes bases e diferentes alturas e, com os resultados fornecidos pelo programa, chegar a 
uma ideia geral verificando, de forma experimental, que o produto da base com a altura resulta na área do polígono. Gimenes $(2014$, p. 10) verificou que neste caso o aluno “estabelece relações lógicas entre as propriedades das figuras (a altura é uma reta perpendicular, pode ocupar os três lados do triângulo), relaciona uma determinada propriedade como sequência de outra. Aspectos considerados no nível da dedução formal". Um outro aspecto descrito na pesquisa de Gimenes (2014) foram as facilidades oferecidas pelo Geogebra, pois ele fornece o cálculo de área de forma imediata, que pode ser utilizado após a realização dos cálculos pelos alunos para a verificação do resultado.

\section{CONSIDERAÇÕES FINAIS}

Ao avaliar características do processo de pensamento do aluno quando utilizadas atividades exploratórias investigativas com o computador, consideramos uma contribuição na produção do conhecimento geométrico a diversidade de respostas dadas pelos alunos e os momentos de dúvidas e incertezas que tais construções geraram em sala de aula. As informações surgidas possibilitam ao professor entender a linha de raciocínio do aluno, ou mesmo os conhecimentos que o aluno já dispunha sobre um determinado assunto. De acordo com Ponte e Segurado (2008, p. 01), os processos exploratório-investigativos ampliam as oportunidades ao aluno de "generalizar, considerar casos particulares, simbolizar, comunicar, analisar, explorar, conjecturar e provar". São ações que colocam o aluno no centro do processo educativo.

As atividades descritas colaboraram no aspecto relacionado à visualização, proporcionaram a experimentação e análises informais das próprias construções pelos alunos. Ao solicitar a justificativa de tais opções de resposta o aluno foi provocado a procurar argumentos, e as construções geométricas geraram dúvidas e incertezas, contribuindo para a busca por repostas a partir da necessidade de atingir determinado objetivo, o que torou as informações significativas para o aluno. A atividade I exigiu do aluno uma análise das propriedades, e as construções realizadas com programa de geometria dinâmica colaboraram no sentido de 
fortalecer o conhecimento relacionado a características de triângulos, como a soma dos ângulos internos, análise das possíveis relações na classificação de triângulos quanto às medidas de seus lados e às medidas de ângulos, fornecendo uma base de conhecimentos importante para o assunto congruência e semelhança de triângulos.

A experiência criou oportunidades para o professor analisar o raciocínio geométrico dos alunos e avaliar aspectos dentro das atividades a serem propostas, como análise, visualização, classificação e deduções informais, oferecendo ao aluno oportunidade de construir os alicerces para o raciocínio lógico dedutivo. De Villiers (2010), Santos (2008) e Javaroni (2007) discutem as possíveis contribuições que determinados softwares podem ter na ligação entre a exploração indutiva e o desenvolvimento do raciocínio dedutivo. De Villiers aponta a importância em proporcionar um alicerce visual intuitivo para diferentes assuntos geométricos, "que depois podem ser tratados de maneira mais formal em um contexto dedutivo" (2010, p. 407).

O programa de geometria dinâmica no ensino de geometria, nesta experiência, ofereceu oportunidade ao aluno de sistematizar propriedades, realizar explicações lógicas e realizar uma geometria experimental e indutiva. A reflexão que fica e certamente aponta para a realização de novos trabalhos é qual a melhor forma do uso destes recursos para o avanço do raciocínio lógico dedutivo do aluno.

\section{REFERÊNCIAS}

BORBA, M. C. A pesquisa qualitativa em educação matemática. Anais da 27 a reunião anual da Anped - Caxambu, MG, 21-24 nov. 2004.

BORBA, M. C.; VILLARREAL, M. E. Humans-With-Media and the Reorganization of Mathematical Thinking: information and communication technologies, modeling, experimentation and visualization. New York: Springer, 2005. Disponível em: <http://books.google.com.br/books>. Acesso em: 6 dez. 2014. 
CROWLEY, M. L. O modelo van Hiele de desenvolvimento do pensamento geométrico. Aprendendo e ensinando geometria. São Paulo: Atual, 1994.

DE VILLIERS, M. Algumas reflexões sobre a Teoria de Van Hiele. São Paulo: Matemática, v. 12, n. 3, p. 400-431, 2010. Disponível em: <http://revistas.pucsp.br/index.php/emp/article/download/5167/3696>. Acesso em: 27 jul. 2014.

GARNICA, A. V. M. História Oral e educação Matemática. Em: BORBA, M. C.; ARAÚJO, J. L. (Org.). Pesquisa Qualitativa em Educação Matemática. Belo Horizonte: Autêntica, 2004.

GIMENES, S. S. Contribuições de atividades de investigação e exploração com o computador na produção de conhecimento acerca do assunto semelhança. Dissertação de Mestrado. Programa de Pós-Graduação Mestrado Profissional e Educação Ciência e Matemática. Instituto Federal do Espírito Santo, 2014.

GOLDENBERG, M. A arte de pesquisar: como fazer pesquisa qualitativa em Ciências Sociais. 8a ed. Rio de Janeiro: Record, 2004.

JAVARONI, S. L. Abordagem geométrica: possibilidades de ensino e aprendizagem de introdução às equações diferenciais ordinárias. Tese (Doutorado em Educação Matemática) Instituto de Geociências e Ciências Exatas, Universidade Estadual Paulista, Rio Claro, 2007.

KALEFF, A. M. M.R. Novas tecnologias no ensino da matemática: tópicos em ensino de geometria. Universidade Aberta do Brasil -UAB, Rio de Janeiro: 2008.

LABORDE, C. Relationships between the spatial and theoretical in geometry: the role of computer dynamic representations in problem solving. Em: INSLEY, D., JOHNSON, D.C. Information and communications technologies in school mathematics. Grenoble: Champman and Hall, 1998.

PONTE, J. P., BROCARDO, J. OLIVEIRA, H. Investigações Matemáticas na Sala de Aula. Belo Horizonte: Autêntica, 2009.

SANTOS, S. C. A Produção Matemática em um Ambiente Virtual de Aprendizagem: o caso da geometria euclidiana espacial. 145 f. Dissertação (Mestrado) - Universidade Estadual Paulista, 2006.

ZULATTO, R. B. A. I. Docentes da UNESP: a natureza da aprendizagem matemática em um ambiente online de formação continuada de professores. 2007. 174 f. Tese (Doutorado em Educação). Universidade estadual Paulista, São Paulo, 2007. 